\title{
Function Generator using Current Conveyor (CCII)
}

\author{
Dileep Kumar Patel \\ Student, \\ M. Tech, E \& I Department, \\ Shri G.S. Institute of \\ Technology and Science, Indore
}

\author{
Rajesh Khatri \\ Assistant Professor \\ E \&l Department, \\ Shri G.S. Institute of Technology \\ and Science, Indore
}

\begin{abstract}
In this paper, current-mode based solution suitable for sinusoidal, triangular and square wave generator using second generation current conveyor (CCII) is designed. This is based on current mode trans-linear scheme, with independent control of frequency are presented in this paper. The configuration consists of a second-generation conveyor (CCII), a schmitt trigger, a current mode integrator and a capacitor that is responsible for better linearity. The proposed oscillator, which utilizes a second generation current conveyor (CCII) as a active element, The frequency of the function generators can be adjusted with bias current of current conveyor (CCII) circuit. The performance of the circuit is checked through spectre simulation tool of cadence with $180 \mathrm{~nm}$ technology. The measured results included in the paper show better linear variation of frequency as compared with existing reported configurations over the range from 112 to $376 \mathrm{MHz}$.
\end{abstract}

\section{Keywords}

Current mode oscillator, Current conveyor (CCII), Schmitt trigger, Current mode integrator.

\section{INTRODUCTION}

Oscillators are most useful electronic circuits that generates periodic AC waveforms (e.g., sinusoidal, square or triangular). Sinusoidal Square and triangular waveform generators of variable frequency has a wide range of applications in the field of telecommunication, signal processing, control systems, measurement system and sensor interfacing, particularly depending on their operating frequency range. A number of square/triangular wave generator circuits have been designed using voltage- mode operational amplifier as active element. These circuits generate the waveform by charging and discharging effect of resistance-capacitance (R-C) cell, followed by a hysteresis comparator. It is well known that the dynamic range of voltage-mode oscillators is dictated by frequency-dependent gain of operational amplifier. This problem can be solved by current mode $(\mathrm{CM})$ approach, There is a number of different oscillators have been proposed based on current mode approach $(\mathrm{CM})$ approach, in present the main focus of researchers is to decrease the number of active and passive components while maintaining wide operating frequency range It has also been seen that the second-generation current conveyor (CCII) is very useful as an analog building block and is receiving regular attention in waveform generators, oscillators, and design of filters. The second generation current conveyor (CCII), which shows large dynamic range, wide bandwidth, high linearity, possibility of design using low power consumption and simple analog circuit designing. The current conveyor relies upon the ability of the circuit to act as a voltage buffer between its inputs and the ability to convey current between two ports at extremely different impedance levels. In this paper, a novel CM based function generator using single current conveyor (CCII), a schmitt trigger, a current mode integrator circuit and a capacitance is proposed, which neglect the effect of voltage/current saturation thus provide wide dynamic range. In this, first we designed sinusoidal oscillator which generate sine wave then with the help of this we generate square and triangular wave. The sinusoidal oscillator simply designed with a current conveyor (CCII) and a capacitance and the frequency of the oscillator can be adjusted with dc bias current. In this way, there is no limitation in wide frequency range and it is also possible to set the circuit sensitivity and operating frequency range. Simulation and experimental results shows a good agreement with theoretical expectations with good linearity in wide dynamic frequency range with bias current. In comparison to other solutions the benefits of our proposal are capability of providing wide oscillating frequency range with acceptable non-linearity, required less number of active and passive components.

\section{CURRENT CONVEYOR}

In 1968 sedra and smith first introduced current conveyor named as first generation current conveyor (CCI). Current conveyor can provide better gain-bandwidth products than compare to op-amps. There is three generation of current conveyor named as first generation current conveyor (CCI), second generation current conveyor (CCII) and third generation current conveyor (CCIII).

\subsection{Second Generation Current Conveyor}

Second generation current conveyor (CCII) relies upon the ability of the circuit to act as a voltage buffer between its inputs and the ability to convey current between two ports at extremely different impedance levels.

Fig. 1 shows the symbol of CCII, characteristics of CCII can be described as:

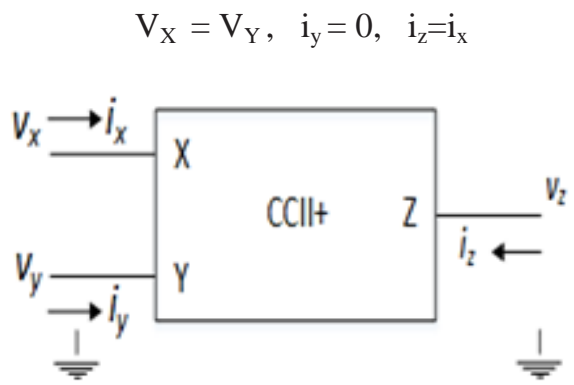

Fig.1 Symbol of CCII

The output current $i_{z}$ depends on input current $i_{x}$, which may be directly injected by applying voltage at $\mathrm{X}$ node, or by copy the input voltage from terminal Y.

\section{RELATED WORK}

Previous design shows resistance-capacitance $(R C)$ square/triangular waveform generators [7] using second 
generation current conveyor which is designed from voltage mode op-amp based schemes with control of frequency is independent. The waveform generator consist two second generation current conveyors, 3 resistors, and a floating capacitor which constrained for better linearity. The frequency of the waveform generator can be varied with passive component. The result of resistance-capacitance $(R C)$ square/triangular waveform generators showed that the frequency variation from $25 \mathrm{~Hz}$ to $260 \mathrm{kHz}$.

\section{PROPOSED FUNCTION GENERATOR 4.1 CCII Oscillator}

Second generation current conveyor is the basic building block of our circuit. It is possible to design oscillator with

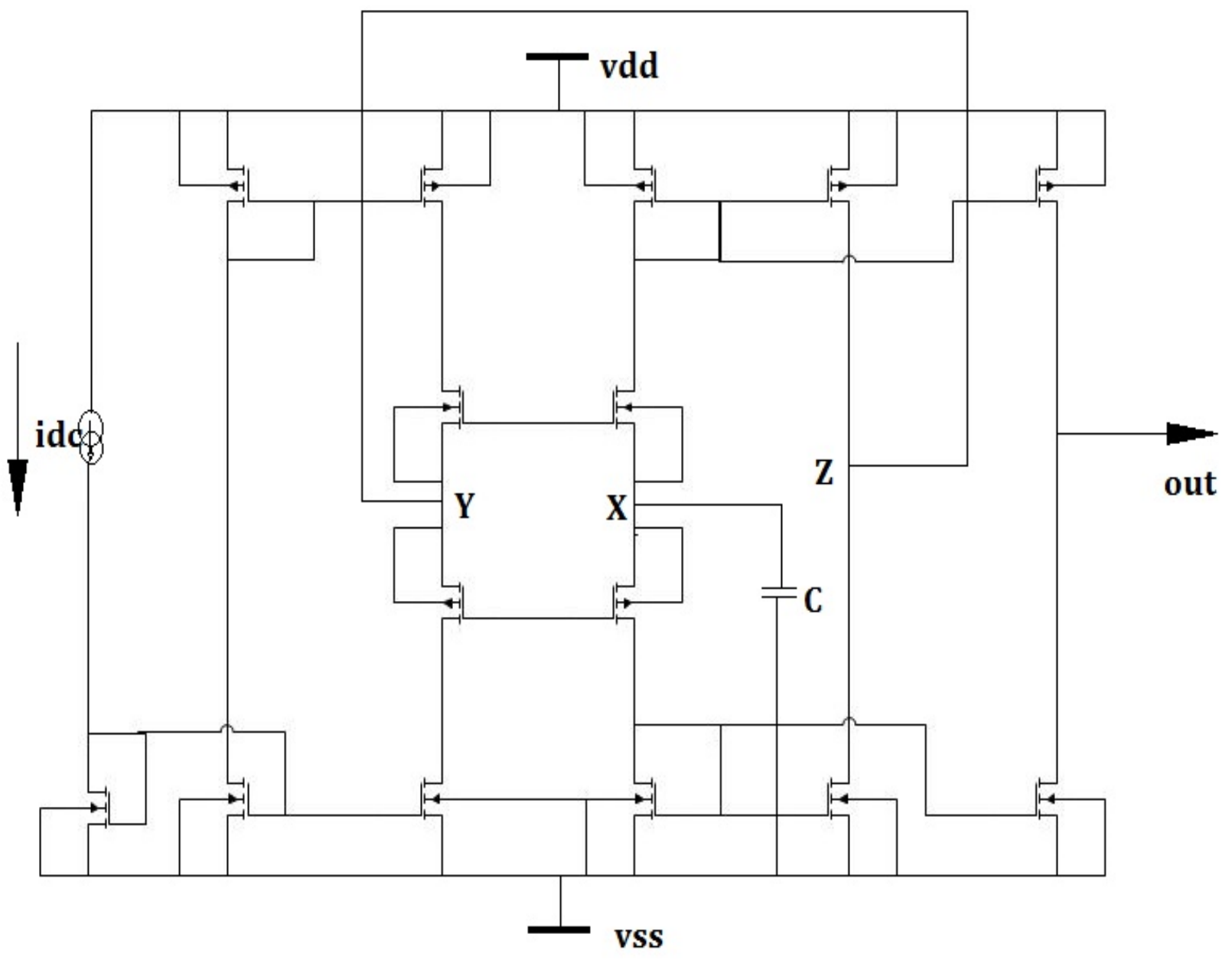

Fig.-2 CCII Oscillator

single current conveyor. CCII oscillator is basically based on current mode (CM) approach. Oscillator can be easily design with second generation current conveyor (CCII) and a capacitor. The oscillator using CCII is shown in fig. 2 which is derived with trans-linear scheme, in which $\mathrm{z}$ terminal is feedback to y terminal of CCII and a capacitor is connected to $\mathrm{x}$ terminal of CCII which is constrained better linearity and terminal out provide us sine wave. Here the current conveyor operating at $1 \mathrm{~V}$ supply.

\subsection{Integrator Circuit}

Fig.-3 shows the circuit implementation of current mode current integrator circuit. Where $\mathrm{I}_{1}, \mathrm{I}_{2}, \mathrm{I}_{3}$ are fixed dc current for integrator circuit and the value is $10 \mathrm{uA}$. At the input port of integrator circuit current square wave is given and triangular wave is produced at the output or triangular port.

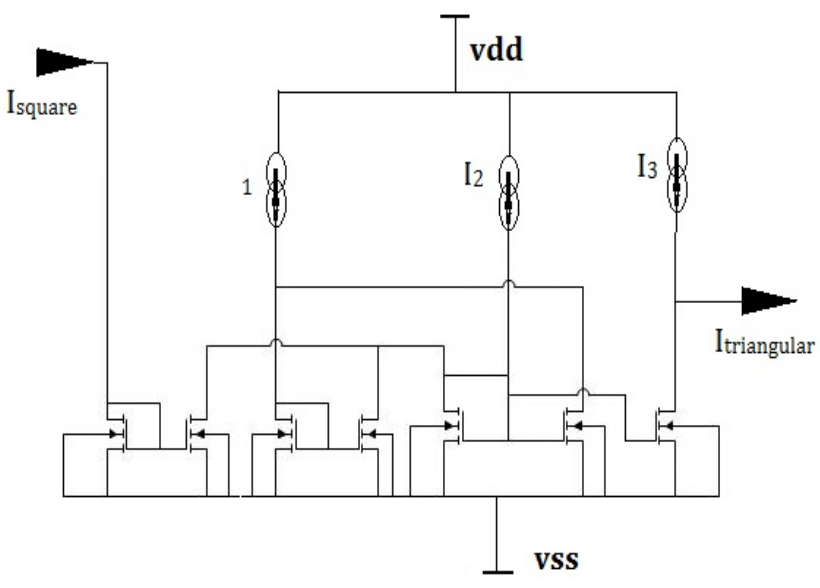

Fig.-3 Integrator Circuit 


\subsection{Function Generator}

Fig.-4 shows the block diagram of function generator, it consist a current mode oscillator, a Schmitt trigger circuit and a current mode integrator circuit. The current mode oscillator generates sinusoidal wave and the output sinusoidal voltage is given to the Schmitt trigger circuit which generates square wave by converting the saturation current into saturation voltage, and the output current of Schmitt trigger circuit in current form is given to the current mode integrator circuit which generate the triangular wave at the output and the dc voltage level of triangular wave is shifted positive half due to the dc current sources presented in the integrator circuit

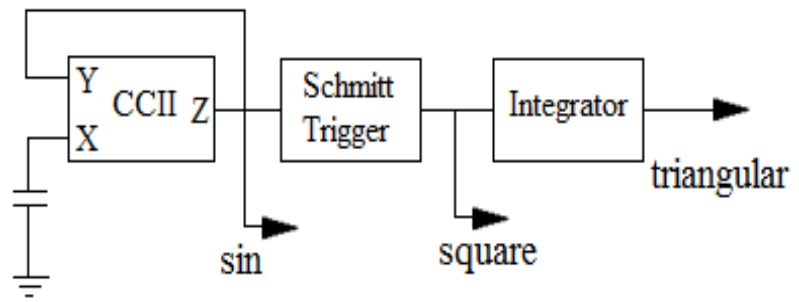

Fig.-4 Block diagram of Function Generator

\section{SIMULATION RESULT}

The circuit in fig.-5 is simulated in cadence with spectre simulation tool and the supply voltage for the circuit is $1 \mathrm{~V}$ and the bias current is varied $20 \mathrm{uA}$ to $80 \mathrm{uA}$, and $\mathrm{I}_{1}, \mathrm{I}_{2}, \mathrm{I}_{3}$ is fixed at $10 \mathrm{uA}$. When the dc bias current is in the range $40 \mathrm{uA}$ to $80 \mathrm{uA}$ the circuit provides better oscillations.

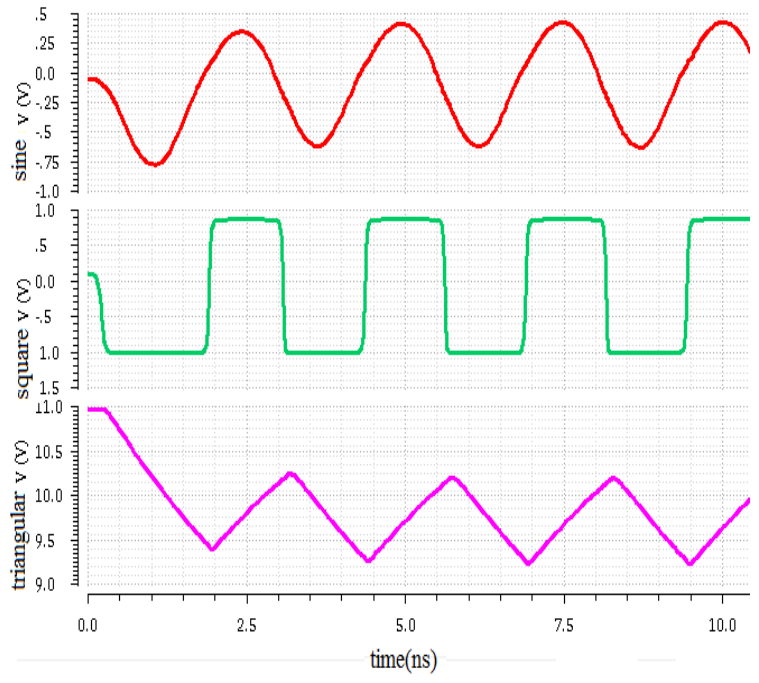

Fig.-5 Output waves

The output of the current mode oscillator gives better sinusoidal wave and the output waves of the function generator are shown in fig.5, different waves is shown in fig.5 , sinusoidal, square and triangular where sinusoidal wave is the output of oscillator and square and triangular waves are the output waves of Schmitt trigger and integrator circuit, from the fig.-5 it is also clear that the frequency of all waves is same.

Fig.-6 shows the graph between dc bias current $\left(\mathrm{I}_{\mathrm{dc}}\right)$ and frequency. It is also observed that as the dc bias current $\left(\mathrm{I}_{\mathrm{dc}}\right)$ of the current conveyor circuit is varied the frequency is also varied this variation is shown in fig-5, from the graph It is clear that as bias current increases $\left(\mathrm{I}_{\mathrm{dc}}\right)$ the frequency is also increases.
The power consumption is also an important parameter for any design circuit, fig.-7 shows the graph between power dissipation and bias current, which shows power dissipation in the circuit is lies between $2.2 \mathrm{~mW}$ to $5.5 \mathrm{~mW}$ as bias current increases the power dissipation increases.

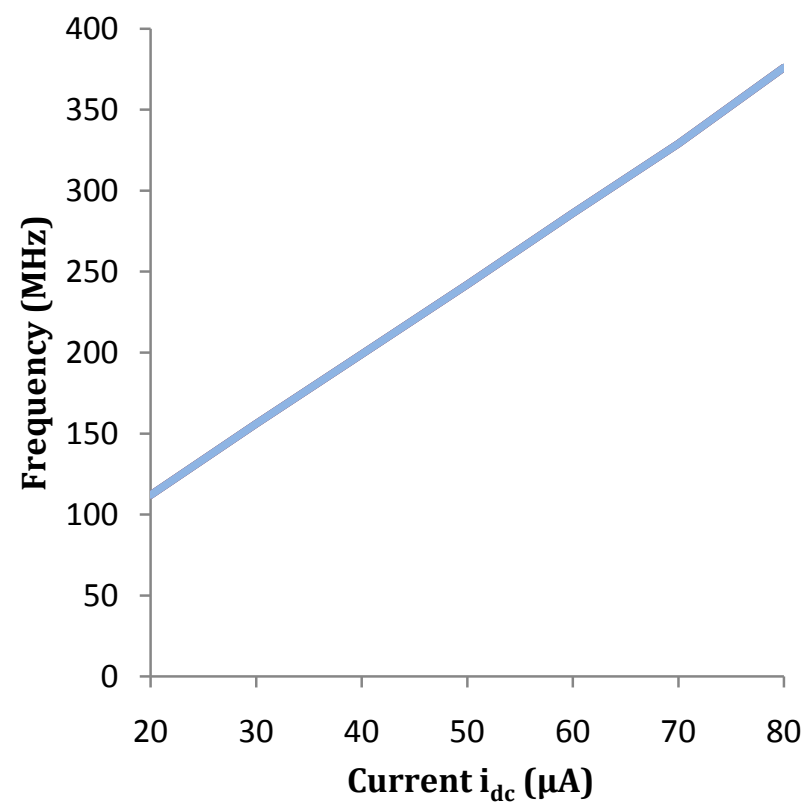

Fig.-6 $i_{d c}$ vs. Frequency

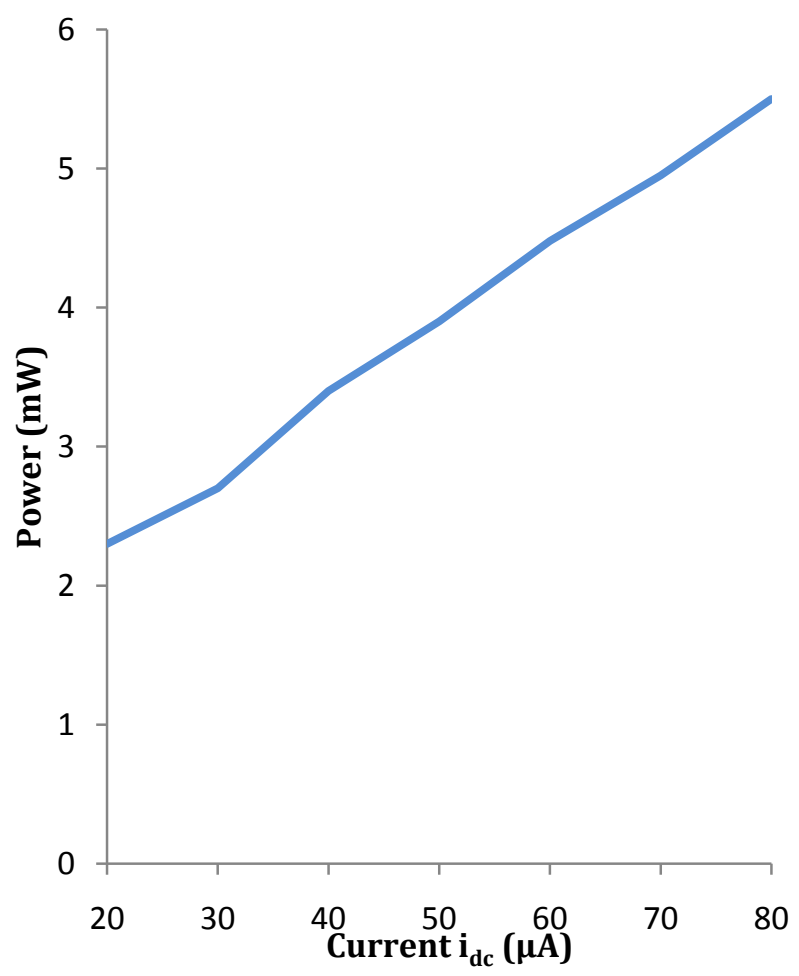

Fig.-7 idc vs. Power

From the simulation results the various parameters of the current conveyor based function generator can be tabulated as: 
Table-1 Output Results

\begin{tabular}{|l|l|}
\hline Parameter Name & Range \\
\hline Bias Current $\left(\mathrm{i}_{\mathrm{dc}}\right)$ & $20 \mu \mathrm{A}-80 \mu \mathrm{A}$ \\
\hline Oscillating Frequency & $112 \mathrm{MHz}-375 \mathrm{MHz}$ \\
\hline Power Dissipation & $2.2 \mathrm{~mW}-5.5 \mathrm{~mW}$ \\
\hline
\end{tabular}

\section{CONCLUSION}

The simulation results showed that the proposed function generator have better linearity and the frequency range is also improve and can varies from $112 \mathrm{MHz}$ to $375 \mathrm{MHz}$ and passive component is reduced. It is also seen that oscillation frequency is changed according to the bias current and in addition it does not depend on supply voltage. The function generator gives better response when its bias current is in the range $40 \mathrm{uA}$ to $80 \mathrm{uA}$. The power dissipation is less as compare to previous and maximum power dissipation is $5.5 \mathrm{~mW}$.

\section{REFERENCES}

[1] W.-S. Chung, H. Kim, H.-W. Cha, and H.-J. Kim, "Triangular/square-wave generator with independently controllable frequency and amplitude," IEEE Trans. Instrum. Meas., vol. 54, no. 1, pp. 105-109, Feb. 2005.

[2] A. Sedra and K. C. Smith, "A second-generation current conveyor and its applications," IEEE Trans. Circuit Theory, vol. CT-17, no. 1, pp. 132-134, Feb. 1970.

[3] A. S. Sedra, G. W. Roberts, and F. Gohh, "The current conveyor: History, progress and new results," Proc. Inst.
Elect. Eng.-Part G, vol. 137, no. 2, pp. 78-87, Apr. 1990.

[4] G. Norinand, "Translinear current conveyors", lnt. J.Electronics, vol. 59, No. 6, pp. 771-777, 1985.

[5] M. T. Abuelma'atti and S. M. Al-Shahrani, "New CFOA-based triangular/ square wave generator," Int. J. Electron., vol. 84, no. 6, pp. 583-588, Jun. 1998.

[6] Dipankar Pal, Avireni Srinivasulu, Basab Bijoy Pal, Andreas Demosthenous, "Current Conveyor-Based Square/Triangular Waveform Generators With Improved Linearity" IEEE transaction on Instrument and measurement, vol. 58, no. 7, July 2009.

[7] M. T. Abuelma'atti and M. A. Al-Absi, "A current conveyor-based relaxation oscillator as a versatile electronic interface for capacitive and resistive sensors," Int. J. Electron., vol. 92, no. 8, pp. 473-477, Aug. 2005.

[8] A. M. Soliman, "A novel variable frequency sinusoidal oscillator using a single current conveyor," Proc. of IEEE, vol.66, no.7, pp. 800-800, 1978.

[9] A. D. Marcellis, C. D. Carlo, G. Ferri and V. Stornelli, "A CCII-based wide frequency range square waveform generator,” Int. J. Circuit Theory Appl., vol. 41, pp. 1-13, March 2013.

[10] H. O. Elwan and A. M. Soliman, "Low-voltage lowpower CMOS current conveyors," IEEE Trans. Circuits Syst. I, vol. 44, pp. 828-835, Sept. 1997. 